\title{
CARACTERIZAÇÃO E ACEITABILIDADE DE TOMATE SECO
}

\section{CHARACTERIZATION AND ACCEPTANCE OF DRIED TOMATO}

\author{
Cláudia Leite Munhoz ${ }^{1}$, Tiemi Umebara ${ }^{2}$, \\ Ivanise Guilherme Branco ${ }^{3}$, Eliana Janet Sanjinez-Argandoña ${ }^{4}$ \\ ${ }^{1}$ Universidade Federal de Mato Grosso do Sul - Campo Grande - Brasil clmunhoz@yahoo.com.br \\ ${ }^{2}$ Universidade Federal do Paraná - Curitiba - Brasil tiemi_tiemi@ hotmail.com \\ ${ }^{3}$ Universidade Estadual Paulista - Assis - Brasil ivanisebranco@bol.com.br \\ ${ }^{4}$ Universidade Federal da Grande Dourados - Dourados - Brasil elianaargandona@ ufgd.edu.br
}

\begin{abstract}
Resumo
Neste trabalho avaliou-se o conteúdo de vitamina $C$ e de carotenóides totais em tomates frescos e desidratados para conserva, com posterior imersão em molho para avaliar sua preferência e aceitabilidade sensorial. A desidratação foi realizada em secador com fluxo de ar a $70{ }^{\circ} \mathrm{C}$ até obtenção de um produto com umidade final de 45\%. Foram realizadas determinações de ácido ascórbico, sólidos solúveis, acidez, açúcares e carotenóides totais antes e após o processo de desidratação. Os tomates desidratados foram imersos em três tipos de molhos (de pimenta, de orégano com folhas de louro e de alho) por 25 dias. Após esse período, os tomates secos em conserva foram submetidos à análise sensorial na forma de patês, aplicando-se teste de preferência. Os resultados mostraram que houve retenção de vitamina $C$ e de carotenóides totais de $14,0 \%$ e 44,3\%, respectivamente, no tomate após o processo de desidratação. Dentre as formulações de conserva verificou-se que não houve diferença sensorial significativa ao nível de $5 \%$ entre os patês, sendo todas as formulações aceitas.
\end{abstract}

Palavras-chave: Lycopersicum esculentum Mill; análise sensorial; tomate seco; vitamina C; carotenóides.

\section{Introdução}

O tomate (Lycopersicon esculentum Mill) é um dos vegetais mais produzidos no mundo. No Brasil, representa uma das culturas nacionais de maior importância econômica, sendo industrializados na forma de inúmeros produtos como sucos, purês, molhos, extratos e pastas (AKANBI et al., 2006). Mais recentemente tem sido amplamente utilizado como tomate seco em conserva.

A importância do tomate na alimentação é atribuída por apresentar, além das propriedades nutricionais básicas, propriedades benéficas na redução do risco de doenças crônico degenerativas. Os carotenóides presentes no fruto são os principais responsáveis por essas propriedades, dos quais 
o licopeno apresenta maior contribuição. $O$ crescente interesse na atividade antioxidante do carotenóide licopeno se deve à alegação de que esse poderoso antioxidante combate os radicais livres, retarda o envelhecimento e pode proteger contra o câncer, inclusive o de próstata (RAUPP et al., 2009).

A vitamina $\mathrm{C}$ também é um antioxidante que, de acordo com vários pesquisadores, reduz o risco de ateroscleroses, doenças cardiovasculares e algumas formas de câncer (HARRIS, 1996; LI e SCHELLHORN, 2007). No entanto, é muito sensível à destruição quando o produto é submetido a condições adversas de estocagem, altas e baixas temperaturas, baixa umidade relativa e danos físicos (SANJINEZ-ARGANDOÑA et al., 2005; TORREGGIANI e BERTOLO, 2001 ). O ácido ascórbico é facilmente oxidado, especialmente em soluções aquosas, e altamente favorecido pela presença de oxigênio e metais pesados (especialmente $\mathrm{Cu}^{+2}, \mathrm{Ag}^{+2}, \mathrm{Fe}^{+3}$ ) em $\mathrm{pH}$ alcalino e alta temperatura. Em processos de conservação como a secagem, a degradação da vitamina $C$ chega a ser de 100\% (PADULA e RODRIGUEZ-AMAYA, 1987; TORREGGIANI e BERTOLO, 2001). Técnicas que preservem ou favoreçam sua retenção durante o processamento e armazenamento, são foco da pesquisa atual. Por outro lado, a degeneração dos carotenóides, com concomitante perda da cor e da vitamina A, é um problema comum no processamento e armazenamento de frutas (PADULA e RODRIGUEZ-AMAYA, 1987). Várias pesquisas constataram que quanto menor a temperatura e o tempo de cozimento, maior a preservação do conteúdo de alfa-caroteno, betacaroteno e carotenóides totais (SANT'ANA et al., 1998; SHI et al., 1999), visto que o tratamento térmico inativa as enzimas responsáveis pela biossíntese dos carotenóides e estimula a isomerização e oxidação destes compostos, resultando em perdas.

O tomate seco chegou ao mercado nacional, vindo de outros países, particularmente da Espanha e da Itália (CAMARGO et al., 2007). No Brasil, a produção de tomate seco geralmente é realizada de maneira artesanal. Entretanto, carecem de padronização e poucos trabalhos são encontrados na literatura em relação ao processo de desidratação, à adição de especiarias e à preferência sensorial.

Apesar das transformações que ocorrem nos alimentos durante a secagem ou desidratação é possível minimizar perdas de qualidade por meio de técnicas de seleção apropriada e da padronização do material, do controle operacional nas etapas do processo e das condições de armazenamento do produto (WATADA e QI, 1999; PESIS et al., 2000). Os tomates secos encontrados no mercado apresentam variabilidade significativa quanto às características de textura $\mathrm{e}$ de cor, apresentando produtos mais ou menos macios, escuros ou claros. Esses parâmetros estão 
diretamente relacionados com a temperatura e o tempo de secagem, influenciando na aceitabilidade do produto pelo consumidor (BORDERÍAS e MONTERO, 1988).

Atualmente, com mercados multinacionais e competitivos, o sucesso de um produto depende não só dos aspectos de eficiência do processo e viabilidade econômica, mas, também, da satisfação ao sabor e expectativas do consumidor. Levar em consideração esses fatores é essencial no processo de desenvolvimento e melhoria da qualidade dos produtos e, diante disso, a análise sensorial se constitui em importante ferramenta (CAMARGO et al., 2007).

Os objetivos deste trabalho foram avaliar os teores de vitamina $\mathrm{C}$ e de carotenóides totais presentes no tomate desidratado e avaliar a preferência e aceitabilidade sensorial de patês de tomate seco em conserva com diferentes molhos de imersão.

\section{Material e métodos}

\section{Material}

Foram utilizados tomates (Lycompersicon esculentum Mill) de mesa cv Carmem. Os frutos de vez foram adquiridos no mercado local de Guarapuava-PR, juntamente com os condimentos e as especiarias.

\section{Métodos}

\section{Desidratação do tomate seco}

Os frutos (20 kg) foram acondicionados em caixa plástica de polipropileno $(555 \mathrm{~mm}$ comprimento x $360 \mathrm{~mm}$ largura x $210 \mathrm{~mm}$ altura $)$ e mantidos à temperatura ambiente $\left(24 \pm 2{ }^{\circ} \mathrm{C}\right)$ até que apresentem a cor adequada para realizar os experimentos, definida pela cor vermelha, seguindo o padrão de cores disponibilizada na carta de comercialização do Programa Horti \& Fruti de produtos hortigranjeiros (CEAGESP, 2005) para realizar os experimentos. Os frutos foram imersos em solução de hipoclorito de sódio $(1 \%)$ à temperatura ambiente $\left(24 \pm 2{ }^{\circ} \mathrm{C}\right)$, por dez minutos, para desinfecção.

Após sanificados, os tomates foram cortados longitudinalmente em quatro partes, removendo-se as sementes. Os pedaços de tomates foram lavados em água destilada, secos com papel absorvente, distribuídos em bandejas e colocados no secador. O processo de secagem foi realizado em secador de bandejas à temperatura de $70{ }^{\circ} \mathrm{C}$ com velocidade do ar de secagem de 0,50 $\mathrm{m} \mathrm{s}^{-1}$. As amostras foram desidratadas em dez horas de processo, com conteúdo de umidade final de $45 \%$ (umidade em base úmida). O tempo de secagem foi previamente definido através da cinética 
de secagem (dados não apresentados neste trabalho). Uma alíquota do tomate desidratado foi separada para análises. Ao final da secagem, o produto foi conservado em potes de polietileno teraftalato (PET) hermeticamente fechados durante 48 horas à temperatura de $5 \pm 2{ }^{\circ} \mathrm{C}$ até serem utilizados na elaboração de conservas.

\section{Formulação dos molhos para conserva}

Foram elaboradas três formulações de molhos constituídas de uma mistura básica de azeite de oliva extra virgem (18\%), óleo de soja (80\%), sal (1\%) e 1\% de especiarias (pimenta do reino, orégano e folhas de louro ou alho). A formulação 1 consistiu na adição de pimenta do reino (1\%), a formulação 2 adição da mistura de orégano e folhas de louro (1\%) e formulação 3: adição de alho fresco (1\%), obtendo-se os três tipos de molhos: molho de pimenta, molho de orégano com folhas de louro e molho de alho.

Os tomates em conserva foram elaborados colocando-se três partes de tomate para duas partes de molho em recipientes de vidro, previamente esterilizados, sendo posteriormente hermeticamente fechados e pasteurizados. A quantidade de molho adicionado na conserva (40\%) foi maior que a recomendada pela legislação, para facilitar a distribuição do molho entre os pedaços de tomate desidratado e a transferência de massa durante o tempo de armazenamento. O produto em conserva foi mantido por um período de 25 dias a temperatura ambiente para ser avaliado sensorialmente.

\section{Análises físicas e químicas}

Para as análises físicas e químicas foram utilizadas amostras de tomate fresco e desidratado, triturados separadamente em liquidificador doméstico. Os teores de umidade foram determinados por gravimetria em estufa a $70{ }^{\circ} \mathrm{C}$ por 24 horas, os açúcares totais foram determinados por método de Lane-Eynon baseado na oxidação do cobre, o teor de cinzas foi realizado por incineração em mufla a $550{ }^{\circ} \mathrm{C}$ e a acidez titulável foi determinada por titulação com hidróxido de sódio $0,1 \mathrm{~N}$, todas as análises foram determinadas segundo a AOAC (1996). A quantificação da vitamina C foi realizada por método titulométrico como descrito por BENASSI (1990) e os carotenóides totais foram determinados de acordo com o procedimento descrito por SÁ (2001). O pH foi determinado por leitura direta em potenciômetro e os sólidos solúveis $\left({ }^{\circ}\right.$ Brix) por refratometria utilizando refratômetro $\mathrm{ABBE}$. Todas as análises foram realizadas em triplicata sendo considerados os valores médios e o desvio padrão. 


\section{Análise sensorial}

A aceitabilidade e preferência do tomate seco em conserva imerso em diferentes molhos foram realizadas aplicando-se teste de escala hedônica de nove pontos, ancorados nos extremos (1) “desgostei muitíssimo” e (9) “gostei muitíssimo" (Quadro 1).

Quadro 1 - Modelo de questionário na análise sensorial de aceitação e preferência

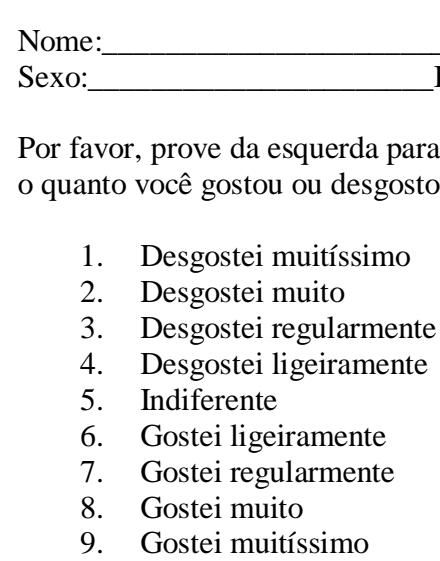

1. Desgostei muitíssimo

2. Desgostei muito

3. Desgostei regularmente

4. Desgostei ligeiramente

5. Indiferente

6. Gostei ligeiramente

7. Gostei regularmente

8. Gostei muito

9. Gostei muitíssimo

Por favor, prove da esquerda para a direita as amostras codificadas de patês e avalie cada amostra usando a escala abaixo para descrever o quanto você gostou ou desgostou do produto. Comente sua escolha.

\begin{tabular}{|l|l|}
\hline Amostra & Valor \\
\hline & \\
\hline & \\
\hline & \\
& \\
\hline
\end{tabular}

Comentários:

O produto foi servido na forma de patê, elaborado com $50 \%$ de tomate seco drenado e $50 \%$ de maionese tradicional comercial (Hellmans $\left.{ }^{\circledR}\right)$, misturados homogeneamente em liquidificador doméstico, obtendo-se um patê para cada conserva de tomate com diferente formulação de molho de imersão.

Quantidade aproximada de $2 \mathrm{~g}$ dos patês foi espalhada em biscoitos "água e sal" (marca Tostines $\left.{ }^{\circledR}\right)$ e servidos em pratos brancos, codificados com números de três dígitos. Foram apresentados ao mesmo tempo a cada julgador três tipos de patê e foi solicitado para que avaliasse, de acordo com a preferência, o quanto gostou ou desgostou das amostras. Também foi oferecida água e solicitou-se a ingestão entre uma amostra e outra. O teste de aceitação foi aplicado no Laboratório de Análise Sensorial de Alimentos do Departamento de Engenharia de Alimentos da UNICENTRO em cabines individuais, com luz branca a temperatura ambiente de $24 \pm 2{ }^{\circ} \mathrm{C}$ para uma equipe de 26 julgadores não treinados, entre alunos e professores do campus, porém, potenciais consumidores de tomate seco, identificados durante o recrutamento. Foi considerada a nota mínima 7,0 para o produto ser aceito sensorialmente. 
A preferência ou rejeição significativa dos produtos elaborados foi avaliada por análise de variância (ANOVA) e a comparação entre as médias pelo teste de Tukey ao nível de 5 \% de significância.

\section{Resultados e discussão}

A Tabela 1 apresenta uma comparação entre as características físicas e químicas da matériaprima in natura e a de dados encontrados na literatura. O conteúdo de sólidos totais, obtidos a partir da umidade em base seca, a acidez e conteúdo de sólidos solúveis foram similares aos valores obtidos por Camargo (2005) e Shi e Lê Maguer (2000). Os mesmos resultados foram obtidos por Romero-Penha e Kieckbusch (2003).

Tabela 1- Características físicas e químicas do tomate cv Carmem

\begin{tabular}{lcc}
\hline Análises & Literatura* & Experimental encontrado \\
\hline $\mathrm{pH}$ & - & $4,3 \pm 0,04$ \\
Sólidos totais (\%) & 4,19 & $5,9 \pm 0,26$ \\
Acidez (\% ác. cítrico) & 0,35 & $0,4 \pm 0,002$ \\
Vitamina C (mg/100g) & 25 & $13,4 \pm 3,88$ \\
Açúcares (\%) & $2-3$ & $3,5 \pm 0,20$ \\
Sólidos solúveis ( ${ }^{\circ}$ Brix) & 4,18 & $4,3 \pm 0,09$ \\
Indice ${ }^{\circ}$ Brix/Acidez & 12,03 & $11,7 \pm 0,27$ \\
Carotenóides (mg g $\left.{ }^{-1}\right)$ & $19,12 * *$ & $16,0 \pm 0,21$ \\
\hline \multicolumn{2}{c}{${ }^{*}$ Fonte: CAMARGO (2005), * SHI e LÊ MAGUER $(2000)$}
\end{tabular}

As diferenças observadas entre os resultados experimentais e os dados da literatura para o fruto fresco podem ser atribuídas às interferências climáticas, época e técnica de plantio, grau de maturação do fruto, entre outros (CHITARRA e CHITARRA, 2005).

Os resultados obtidos nas análises físicas e químicas do tomate, após desidratação, estão apresentados na Tabela 2.

Com relação ao $\mathrm{pH}$, o tomate desidratado apresentou valores de 5,3 $\pm 0,01$ e o fruto in natura de 4,3 \pm 0,04 (Tabelas 1 e 2). É provável que essa diferença esteja relacionada à degradação do ácido ascórbico ocorrida durante a secagem (SANJINEZ-ARGANDOÑA et al., 2005).

Segundo Souza Filho et al. (1999), as perdas de ácido ascórbico durante o processamento térmico estão associadas a uma combinação de perdas por difusão, degradação química e térmica, devido ao efeito do calor. Assim, a desidratação dos tomates à $70^{\circ} \mathrm{C}$ e o oxigênio presente no ar, durante o processo, podem ter favorecido à oxidação do nutriente. Neste sentido, Dewanto et al. 
(2002) ao estudarem a perda de vitamina C no tomate decorrente do processamento, observaram que apesar da perda significativa da vitamina, o processamento térmico favoreceu o valor nutricional do produto pelo aumento do conteúdo de flavonóides disponíveis, os quais têm uma considerável atividade antioxidante. Do exposto, mesmo com a perda da vitamina C, o produto pode ainda manter seu valor nutritivo na forma mais biodisponível após o processamento, segundo estudos realizados por Dewanto et al. (2002), na avaliação da atividade antioxidante em tomates submetidos ao tratamento térmico.

A quantificação da vitamina C no tomate seco foi de $16,7 \mathrm{mg} / 100 \mathrm{~g}$ e no fruto in natura 13,4 $\mathrm{mg} / 100 \mathrm{~g}$, tendo como base o teor de sólidos totais. Observou-se retenção de $14 \%$ da vitamina C no produto, após dez horas de desidratação a $70^{\circ} \mathrm{C}$.

Tabela 2 - Características físicas e químicas do tomate desidratado a $70{ }^{\circ} \mathrm{C}$ por $10 \mathrm{~h}$

\begin{tabular}{lc}
\hline \multicolumn{1}{c}{ Análises } & Valor experimental \\
\hline Umidade (\%) & $45,0 \pm 0,02$ \\
$\mathrm{pH}$ & $5,3 \pm 0,01$ \\
Sólidos totais (\%) & $54,7 \pm 3,99$ \\
Acidez (\% ác. cítrico) & $0,4 \pm 0,01$ \\
Vitamina C (mg/100g) & $9,5 \pm 0,81$ \\
Açúcares (\%) & $30,7 \pm 0,78$ \\
Carotenóides (mg/100g) & $6,5 \pm 0,13$ \\
\hline
\end{tabular}

Os carotenóides compõem um grupo de compostos responsáveis pelas cores amarela, laranja e vermelha de muitos alimentos de origem vegetal. São também citados como responsáveis pela diminuição do risco de doenças como câncer e doenças cardiovasculares (MATIOLI; RODRIGUEZ-AMAYA, 2003). O teor de carotenóides encontrados no fruto fresco $(16,0 \mathrm{mg} / 100 \mathrm{~g})$ foi afetado pelas condições de processo. No entanto, no produto final obteve-se retenção de 44,34 \% $(6,5 \mathrm{mg} / 100 \mathrm{~g})$.

Sanjinez-Argandoña et al. (2005) no processo combinado de desidratação osmótica e secagem de goiabas, obtiveram retenção de $25 \%$ de carotenóides e observaram que a estabilidade dos carotenóides pode ter sido influenciada pela presença do ácido ascórbico nas frutas. Choi et al. (2002) indicaram que o ácido ascórbico parece ter efeito estabilizante sobre os carotenóides. Esses pesquisadores estudaram a interação do ácido ascórbico com pigmentos sobre a qualidade do suco de laranja e relataram que a interação do ácido ascórbico com as antocianinas resultou na degradação de ambos e na diminuição da cor e qualidade nutricional do suco de laranja. No entanto, a perda de carotenóides foi limitada comparada com a perda de antocianinas, sob as mesmas 
condições de armazenamento, provavelmente devido ao efeito estabilizante do ácido ascórbico sobre os carotenóides.

De acordo com Dutcosky (2007) a escala hedônica de nove pontos é a mais amplamente utilizada para estudos de preferência e aceitabilidade dos consumidores, com considerável sucesso. Neste sentido, as médias das notas atribuídas aos patês foram: 6,8 para o patê de tomate seco imerso em molho de pimenta, 7,1 para o molho de alho e 7,2 para molho de orégano com folhas de louro. As diferenças observadas entre as notas atribuídas estão relacionadas à preferência do consumidor por sabores conhecidos (Figura 1). Assim, os julgadores preferiram o patê obtido do tomate seco imerso em molho de orégano com folhas de louro, provavelmente por proporcionar um produto mais aromático. No entanto, todos os produtos foram aceitos.

Figura 1 - Avaliação sensorial de patê de tomate seco obtido de três diferentes molhos de imersão

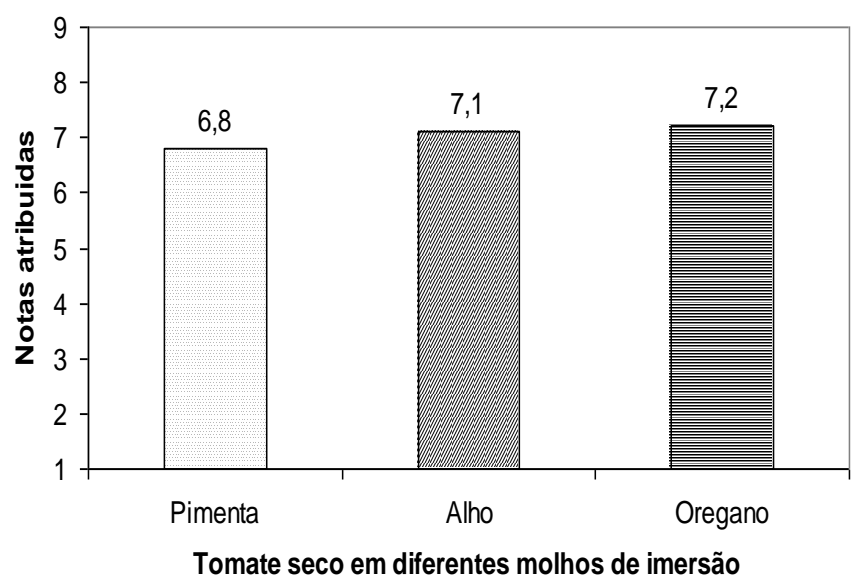

O produto formulado com molho contendo pimenta obteve a menor nota $(6,8)$, mas encontra-se dentro da escala de notas equivalente a "gostei regularmente". Deve-se salientar que o sabor levemente picante foi percebido pelos julgadores, observados nos comentários escritos na ficha sensorial de $65 \%$ dos julgadores.

O tratamento estatístico da análise de variância dos resultados da aceitabilidade (Tabela 3) mostrou que não houve diferença significativa $(p<0,05)$ entre os resultados obtidos para o tomate seco imerso nos diferentes molhos, sendo todos aceitos pelos julgadores.

Tabela 3 - Análise de variância do teste de aceitabilidade

\begin{tabular}{lccccc}
\hline & ${ }^{\circ}$ Graus de liberdade & SQ & SQM & F & F Tabelado(5 \%) \\
\hline Amostra & 2 & 3,00 & 1,5 & 30,76 & 3,19 \\
Julgadores & 25 & 138,89 & 5,56 & & \\
Resíduo & 50 & 99,00 & 1,98 & & \\
Total & 77 & 240,89 & & & \\
\hline
\end{tabular}




\title{
f4. Conclusão
}

Os tomates in natura apresentaram conteúdos de vitamina C de 13,4mg/100 g e de carotenóides totais de $16,0 \mathrm{mg} / 100 \mathrm{~g}$. Com a desidratação a degradação dessas substâncias era esperada. Entretanto o produto desidratado com $45 \%$ de umidade final manteve $14 \%$ da vitamina C e 44,3\% dos carotenóides presentes no fruto in natura.

Os patês de tomates secos imersos em molhos constituídos de orégano e folhas de louro, alho e pimenta tiveram boa aceitação, independente do tipo de molho. O patê de tomate seco imerso em molho de orégano e folhas de louro foi o mais preferido pelos julgadores.

\begin{abstract}
In this work evaluated the content of vitamin $C$ and total carotenoid in tomatoes fresh and dehydrated for conserve, with posterior immersion in sauce, verifying its sensorial acceptability. Dehydration was performed in dryer with airflow at $70{ }^{\circ} \mathrm{C}$ to obtain a product with final moisture of $45 \%$. Determinations were carried out ascorbic acid, soluble solids, acidity, sugars and carotenoid before and after the dehydration process. The dehydrated tomatoes had been immersed in three types of sauces (pepper sauce, oregano with parrot leaves sauce and garlic sauce) per 25 days. After this period, the dry tomatoes in conserve had been submitted to the sensorial analysis in the pate form, applying themselves preference test. The results had been showed that retention of vitamin $C$ and total carotenoid in the dehydrated product showed retention of $14.0 \%$ and $44.3 \%$, respectively, in tomatoes after the dehydration process. Among the formulation of canned tomatoes wasn't found significant difference at $5 \%$ between the pate, and all formulations accepted.
\end{abstract}

Key-words: Lycopersicon esculentum Mill; sensorial analysis; dry tomato; vitamin C; carotenoid.

\section{Referências}

AKANBI, C. T.; ADEYEMI, R.S.; OJO, A. Drying characteristics and sorption isotherm of tomato slices. Journal of Food Engineering, v. 73, n. 2, p. 157-163, 2006. D.O.I:10.1016/j.jfoodeng.2005.01.015

A.O.A.C. Official Methods of Analysis, 13 th ed., Association of Official Analytical Chemists, Washington, 1996.

BENASSI, M. T. Análise dos efeitos de diferentes parâmetros na estabilidade de vitamina C em vegetais processados. 1990. 159p. Dissertação (Mestrado em de Engenharia de Alimentos) - Universidade Estadual de Campinas, Campinas, 1990.

BORDERÍAS, A. J.; MONTERO, P. Fundamentos de la funcionalidad de las proteínas en alimentos. Revista Agroquímica y Tecnologia de Alimentos, v. 28, n. 2, p. 159-169, 1988.

CHITARRA, M. I. F.; CHITARRA, A. B. Pós-colheita de frutas e hortaliças: fisiología e manuseio. Lavras: UFLA, 2005. 785p.

COMPANHIA DE ENTREPOSTOS E ARMAZÉNS GERAIS DE SÃO PAULO. Programa Horti \& Fruti Padrão Classificação do Tomate. Câmara Setorial de Hortaliças do Estado de São Paulo. Disponível em: <http://www.cati.sp.gov.br/novacati/index.php>. Acesso em 12 de abril de 2008.

CAMARGO, G. A. Novas tecnologias e pré-tratamentos: tomate seco embalado a vácuo. 2005. 175f. Tese (Doutorado em Engenharia de Alimentos) - Universidade Estadual de Campinas, Campinas, 2005. 
CAMARGO, G. A.; HAJ-ISA, N.; QUEIROZ, M. R. Avaliação da qualidade de tomate seco em conserva. Revista Brasileira de Engenharia Agrícola e Ambiental, v. 11, n. 5, p. 521-526, 2007. D.O.I: 10.1590/S141543662007000500012

CHOI, M. H.; KIM, G. H.; LEE, H. S. Effects of ascorbic acid retention on juice color and pigment stability in blood orange (Citrus sinensis) juice during refrigerated storage. Food Research International, v. 35, n. 8, p. 753-759, 2002. D.O.I:10.1016/S0963-9969(02)00071-6

DEWANTO, V.; WU, X.; ADOM, F. F. e LIU, R. H. Thermal processing enhances the nutritional value of tomatoes by increasing total antioxidant activity. Journal of Agricultural and Food Chemistry, v. 50, p. 3010-3014, 2002. D.O.I: $10.1021 /$ jf0115589

DUTCOSKY, S. D. Análise sensorial de alimentos. Curitiba: Champagnat, 2007. 239p.

HARRIS, R. S. Subcellular Biochemistry, Ascorbic Acid: Biochemistry and Biomedical Cell Biology. v. 25. Plenum. New York. 1996.

LI, Y.; SCHELLHORN, H. E. New developments and novel therapeutic perspectives for vitamin C. Critical Reviews, v. 137, n. 10, p. 2171-2184, 2007.

MATIOLI, G.; RODRIGUEZ-AMAYA, D. B. Microencapsulação do licopeno com ciclodextrinas. Ciência e Tecnologia de Alimentos, v. 23 (Supl), p. 102-105, 2003. D.O.I: 10.1590/S0101-20612003000400019

PESIS, E.; AHARONI, D.; AHARON, Z.; BEN-ARIE, R.; AHARONI, N.; FUCHS, Y. Modified atmosphere and modified humidity packaging alleviates chilling injury symptoms in mango fruit. Postharvest Biology and Technology, v. 19, n. 1, p. 93-101, 2000. D.O.I:10.1016/S0925-5214(00)00080-6

PADULA, M.; RODRIGUEZ-AMAYA, D. B. Changes in individual carotenoids and vitamin C on processing and storage of guava juice. Acta Alimentaria, v.16, p.209-216, 1987.

RAUPP, D. S.; GARDINGO, J. R.; SCHEBESKI, L. S.; AMADEU, C. A.; BORSATO, A. V. Processamento de tomate seco de diferentes cultivares. Acta Amazônica, v. 39, n. 2, p. 415-422, 2009. D.O.I: 10.1590/S004459672009000200021

ROMERO-PENHA, L. M.; KIECKBUSCH, T. G. Influência de condições de secagem na qualidade de fatias de tomate. Brazilian Journal of Food Technology, v. 6, n. 1, p. 69-76, 2003.

SÁ, M.C. Carotenóides em alimentos preparados para o consumo: Comparação de análise direta e cálculo pelos dados de retenção. 2001. Dissertação (Mestrado em Ciências de Alimentos) - Universidade Estadual de Campinas, Campinas, 2001.

SANJINEZ-ARGANDOÑA, E. J.; MENEGALLI, F. C.; CUNHA, R. L.; HUBINGER, M. D. Evaluation of total carotenoids and ascorbic acid in osmotic pretreated guavas during convective drying. Italian Journal of Food Science, v. 17 , n. 3, p. 305-314, 2005.

SANT'ANA, H. M. P.; STRINGHETA, P. C.; BRANDÃO, C. C.; AZEREDO, R. M. C. Carotenoid retention and vitamin A value in carrot (Daucus carota L.) prepared by food service. Food Chemistry, v. 61, n. 2, p.145-151, 1998. D.O.I:10.1016/S0308-8146(97)00084-8

SHI, J.; LE MAGUER, M. Lycopene in tomatoes: Chemical and physical properties affected by food processing. Critical Reviews in Food Science and Nutrition, v. 40, n. 1, p. 1-42, 2000. D.O.I:10.1080/10408690091189275

SHI, J.; LE MAGUER, M.; KAKUDA, Y.; LIPTAY, A.; NIEKAMP, F. Lycopene degradation and isomerization in tomato dehydration. Food Research International, v. 32, n. 1, p.15-21, 1999. D.O.I:10.1016/S0963-9969(99)00059-9

SOUZA FILHO, M. M; LIMA, J. R.; SOUZA, A. C. R.; SOUZA NETO, M. A. e COSTA, M. C. Efeito do branqueamento, processo osmótico, tratamento térmico e armazenamento na estabilidade da vitamina C de pedúnculos de caju processados por métodos combinados. Ciência e Tecnologia de Alimentos, v. 19, n. 2, p. 211-213, 1999. D.O.I:10.1590/S0101-20611999000200010 
TORREGGIANI, D.; BERTOLO, G. Osmotic pre-treatments in fruit processing: chemical, physical and structure effects. Journal of Food Engineering, v. 49, n. 3, p. 247-253, 2001. D.O.I:10.1016/S0260-8774(00)00210-7

WATADA, A. E.;QI, L. Quality of fresh-cut produce. Postharvest Biology and Technology, v. 15, n. 3, p. 201-205, 1999. D.O.I:10.1016/S0925-5214(98)00085-4

Submetido em 20 fev. 2010; Revisão enviada pelos autores em 21 dez. 2010; Aceito para publicação em 30 jun.2011. 